\title{
The completeness of intervention descriptions in published NIHR HTA funded trials: a cross sectional study
}

\author{
Lisa Douet", Ruairidh Milne, Sydney Anstee, Fay Habens, Amanda Young, David Wright \\ From 2nd Clinical Trials Methodology Conference: Methodology Matters \\ Edinburgh, UK. 18-19 November 2013
}

\section{Objectives}

The objective of this study is to assess whether NIHR HTA funded randomised controlled trials (RCTs) published in Health Technology Assessment journal were described in sufficient detail to replicate in practice.

\section{Methods}

A checklist for assessing intervention descriptions was applied to NIHR HTA funded RCTs published in Health Technology Assessment. The checklist was piloted twice on a sample of 10 reports. Kappa scores were generated to assess agreement in the checklist application. The checklist was modified and applied to all 98 NIHR HTA funded single trial RCTs published in the journal from January 1999 - March 2011. Three assessors independently applied the checklist. Disagreements in scoring were discussed in the team; differences were then explored and resolved.

\section{Results}

Components of the intervention description were missing in 68 / 98 (69.4\%) reports. Baseline characteristics and descriptions of settings had the highest levels of completeness with over $90 \%$ of reports complete. Reports were less complete on patient information with $58.2 \%$ of the monographs having an adequate description. Intervention descriptions were more complete for drug interventions than non-drug interventions with $33.3 \%$ and $30.6 \%$ levels of completeness respectively. Only $27.3 \%$ of RCTs with psychological interventions were deemed to be complete, although numbers were too small for differences to be significant statistically.

NETSCC, University of Southampton, Southampton, UK

\section{Conclusions}

Ensuring the replicability of a study intervention is an essential part of adding value in research. Research funders need to ensure transparency in the reporting of interventions, methods and findings and their responses to identified areas of improvement.

Published: 29 November 2013

doi:10.1186/1745-6215-14-S1-027

Cite this article as: Douet et al:: The completeness of intervention descriptions in published NIHR HTA funded trials: a cross sectional study. Trials 2013 14(Suppl 1):O27.
Submit your next manuscript to BioMed Central and take full advantage of:

- Convenient online submission

- Thorough peer review

- No space constraints or color figure charges

- Immediate publication on acceptance

- Inclusion in PubMed, CAS, Scopus and Google Scholar

- Research which is freely available for redistribution 